\title{
A study of clinical profile and treatment outcome in pre term babies with retinopathy of prematurity
}

\author{
Anupama B ${ }^{1}$, Rashmi Jain ${ }^{2, *}$, Vidya Hegde ${ }^{3}$, Shyam Sudhir ${ }^{4}$, Rashmi Shambhu ${ }^{5}$ \\ ${ }^{\mathbf{1}}$ Assistant Professor, ${ }^{\mathbf{2}}$ Associate Professor, ${ }^{3,4}$ Professor, ${ }^{\mathbf{5}}$ Assistant Professor, ${ }^{\mathbf{1 , 2 , 3}, \mathbf{5}}$ Dept. of Ophthalmology, ${ }^{\mathbf{4}}$ Dept. of Paediatrics, \\ Yenepoya Medical College, Yenepoya Deemed to be University, Mangalore, Karnataka, India
}

*Corresponding Author:

Email: drrashjain@gmail.com

\begin{abstract}
Context: Study of disease and treatment pattern is a key to developing database of Retinopathy of Prematurity (ROP) in India. Aim: To evaluate the pattern of ROP, timing of laser and immediate post laser complications at a tertiary care referral hospital. Study Design: An observational study of preterm babies, screened for ROP from 2008- to 2013 was performed.

Materials and Methods: International classification of ROP was adopted to stage the disease. Information on various parameters including BW, GA, and stage of ROP, treatment details, chronological and post menstrual age (CA and PMA) at laser, number of sittings and immediate complications following laser were collected.

Result: In total data of 233 preterm infants were reviewed. Among the babies screened, 64 (27.8\%) had ROP, out of these 36 babies underwent laser ablation. In one baby with rigid pupil, intravitreal anti Vascular Endothelial Growth factor (VEGF) was given prior to laser. PMA at laser was 30- 48 weeks and the chronological age was 4-18 weeks. PMA at laser of APROP babies was 30 to 32 weeks and the CA at laser was 4 weeks. Post laser complications were recorded in 6 APROP babies. All treated eyes had a favourable outcome except in one eye disease progressed to stage 4B ROP requiring lens sparing vitrectomy.

Conclusion: The study reaffirms the role of GA as the most critical factor in determining the number and severity of ROP. The study validates the need for early screening at 2 weeks. Immediate post laser complications the characteristic of APROP supports single sitting as the most convenient approach to laser.
\end{abstract}

Keywords: Birth weight, Chronological age, Gestational age, Laser therapy, PMA, Preterm infant, Retinopathy of prematurity, Screening.

\section{Introduction}

Retinopathy of Prematurity (ROP) is one of the leading causes of childhood blindness in low and middle income countries, including India. Nearly, 10\% of the global estimate of ROP related blindness and visual impairment in 2010 was from India. ${ }^{1}$ ROP is characterized by abnormal retinal vascularization in preterm infants leading to blindness in untreated cases. Early identification of ROP and timely treatment can prevent complications and the ensuing blindness.

The American screening guidelines for ROP advocate that babies $\leq 1500$ grams birth weight (BW) or $\leq 32$ weeks gestational age (GA) must be screened, with heavier babies to be screened on recommendation by the attending neonatologist. ${ }^{2}$ In developing countries larger babies with a birth weight (BW) of > 1500 grams have also been reported to develop ROP, and hence in counties like India, babies with $\mathrm{BW} \leq 1750$ grams and/or GA of $\leq 34$ weeks are screened. ${ }^{3-6}$ Bigger babies with a GA of 34-36 weeks or 1750- 2000 grams BW are also screened if the baby has risk factors for ROP. ${ }^{7}$ The purpose of current retrospective study was to evaluate the pattern of ROP, timing and outcome of treatment and immediate post laser complications at a tertiary care and referral centre.

\section{Materials and Methods}

An observational study of preterm babies screened for ROP, was performed from 2008 to 2013. This included the babies screened as well as the babies referred after being screened by ophthalmologist for treatment. The study was approved by the institutional ethics committee and has been performed in accordance with the ethical standards as laid down in the 1975 Declaration of Helsinki, as revised in 2000.

The screening was done with binocular indirect ophthalmoscope using infant speculum, depressor under topical anesthesia, Proparacaine Hydrochloride $0.5 \%$, in the neonatal intensive care unit. The pupils were dilated using $0.5 \%$ tropicamide ophthalmic solution and $2.5 \%$ phenylephrine eye drops, half an hour prior to examination.

Retinopathy was graded according to the International Classification of Retinopathy of Prematurity (ICROP). ${ }^{8}$ Babies with treatable ROP were subjected to confluent laser ablation with double frequency Nd: YAG laser under topical anaesthesia (IRIS Medical Oculight SL,810-nm Infrared laser, Iris Medical Inc., Mountain View, CA), as per Early Treatment for Retinopathy of Prematurity (ETROP) guidelines. ${ }^{9}$ The entire procedure was done under topical anaesthesia in the neonatal intensive care unit, under the supervision of attending neonatologist. ${ }^{10}$ All cases were reviewed up to either complete vascularization of the retina or regression of ROP following laser and were included for the purpose of analysis.

Information on various parameters including BW, GA, stage of ROP, details of management, chronological and post menstrual age (CA and PMA 
respectively) at laser, number of sittings and immediate complications following laser were entered in microsoft excel sheet.

The age was categorized in weeks. If the age was 3 days or less, then it was considered to fall in the previous week. Age of more than 3 days, was considered to be equivalent to the next week. Chisquare test was used to test the association between stage of ROP and GA and BW and between CA and PMA at laser, $p$ value less than 0.05 was considered significant.

\section{Result and Discussion}

Records of 233 preterm infants delivered at or referred to the hospital were reviewed. Among the babies screened, 64(27.8\%) had ROP and 27 babies were part of multiple births, of which $51.86 \%(14 / 27)$ had ROP. Number of the babies screened, babies with ROP and those lasered with reference to mean and range of $\mathrm{GA}$ and $\mathrm{BW}$ are depicted in table 1 .

Of the 64 babies with ROP, 33 (51.56\%) had stage 3 ROP, 6 (9.38\%) had Aggressive Posterior ROP (APROP) and one baby had stage $4 \mathrm{~B}$ ROP and the remaining 24 had stage 2 ROP. The number of babies screened $<32$ weeks were $51.5 \%$, but the proportion of these babies having ROP $(\mathrm{N}=64)$ was $78.2 \%$. Although the number of babies screened, weighing $<1500$ grams, comprised $55.8 \%, 77.8 \%(\mathrm{~N}=64)$ of these had ROP. Treatable ROP comprised $56.25 \%$ (36/64) of the ROP babies. All 36 babies underwent laser ablation. One baby required intravitreal injection of Bevacizumab for rigid pupil, prior to laser therapy. Detailed association of GA and BW with stages of ROP and treatment received is depicted in table 1 and 2 . Seven eyes of four APROP babies required two sittings of laser. In 5 of these, it was necessary for completion of laser, while 2 eyes warranted second sitting to treat recurrence of plus disease.

Maximum screened babies were in 32 weeks GA, of which only $5 \%$ required laser, as compared to 34 weeks babies, where $25 \%$ required laser. Fig. 1 depicts a bar graph showing the proportion of screened babies requiring laser, classified according to the gestational age (weeks).

The plot of BW and GA of lasered ROP babies, in the gestational age-specific centile charts, for anthropometry at birth, for south Indian infants is depicted in figure $4 .^{11}$ It was observed that babies <32 weeks, who required laser were scattered around the $50^{\text {th }}$ centile BW. However, most of the 34 weeks GA, lasered babies were below the $10^{\text {th }}$ centile $\mathrm{BW}$.

In the case series, the percentage of babies lasered was $30.6 \%, 52.7 \%, 11.1 \%$ and $5.6 \%$ at the CA of $4,6-$ 8, 9-12 and 13-18 weeks respectively. Eleven babies were treated at 4 week of CA. PMA and CA at laser ranged from 30- 48 weeks and 4-18 weeks respectively. Whereas, PMA and the CA at laser of APROP babies were 30-32 weeks and 4 weeks respectively. Bar charts shown in figure 2 and 3 provides description of association of GA with PMA and CA. All the treated eyes were noted to have a favorable outcome barring one eye, which progressed to stage 4B ROP requiring lens sparing vitrectomy. Post treatment complications were recorded in 6 babies (11 eyes) among the 11 babies treated at the CA of 4 weeks and having GA of $\leq$ 28 weeks. These were noted as early as few hours to one week and resolved within 2 weeks. These included posterior synechiae (rigid pupil), hyphaema, vitreous haze and vitreous hemorrhage in $11,2,9$ and 1 eye respectively. One eye with total hyphaema developed anterior segment ischemia.

In the present study, $27.2 \%$ babies screened (233) had ROP and overall $15.45 \%$ required treatment. The babies requiring treatment constituted $54.5 \%$ of the ROP babies (64). The incidence of ROP and treatable ROP in preterm births, in India ranges from 11.9-52\% and $6.3-44.9 \%$ respectively. ${ }^{12,13}$ The higher incidence of treatable ROP in the current study can be attributed to $66.6 \%$ (24 of 36 babies with treatable ROP) being referred for laser.

The number of babies with ROP decreased proportionate to increase in GA and none of the babies with GA > 35 weeks had ROP. Babies with ROP were almost equally seen across all ranges of $\mathrm{BW}$, but not across all ranges of GA. Similarly, babies with APROP were seen across all ranges of $\mathrm{BW}$ but in relation to GA were limited to $<28$ weeks.

In the present series $27.8 \%(10 / 36)$ of babies with GA $\geq 32$ weeks $(27.8 \% 10 / 36)$ and $8 / 36$ (22.2\%) with $\mathrm{BW}>1500$ had treatable ROP. This observation is in agreement with studies from developing countries. ${ }^{14}$ However, it is uncommon to find treatable ROP in babies > GA 30 weeks in developed countries. ${ }^{15,16}$

When babies with GA at 32 and 34 weeks were looked in isolation (figure1), it was observed that maximum number of babies screened, in this study belonged to GA of 32 weeks, but contributed to only $5 \%$ of treatable ROP, whereas $25 \%$ of the babies in 34 weeks GA had treatable ROP. Lower BW, in higher GA babies, increases the need for treatment as described in the Fig. 4. This validates the need to screen babies with $\mathrm{GA} \geq 34$ weeks in developing countries like India. $^{7}$ There were $6 / 36(15.38 \%)$ babies with APROP with GA $<28$ weeks and mean GA and BW of 27.17 weeks and 1103.33 grams respectively. Babies with higher GA and BW having APROP were also reported by authors from India. ${ }^{17,18}$ PMA and CA of treated babies ranged in the present study from 30-48 and 4-18 weeks and the mean age was 36.85 weeks and 7.1 weeks respectively.

The CA range reported in studies from India and China ranged from1.5- 8.6 and 5.6-7.4 weeks respectively, which was close to our finding. ${ }^{17,19}$ On the contrary much higher CA range at laser, 7.7 - 25 weeks and 17-24 weeks was reported from Sweden and UK respectively. ${ }^{15,16}$ The wide difference in $\mathrm{CA}$ range of 
laser in developing and developed countries mirrors the difference in the quality of neonatal care. ${ }^{15,16}$ These observations emphasize the importance of early screening of preterm babies as per the National Neonatal Foundation (NNF) guideline. ${ }^{17}$ In view of non-progression of retinal vascularization in Zone 3, the laser treatment was delayed in one baby to $\mathrm{CA} 17$ (PMA 47) and in another CA 18 to (PMA 48) weeks. In babies with incomplete peripheral retinal vascularization the recommendation is to laser the avascular retina around PMA of 45 to 50 weeks. $^{20}$

In our series APROP required laser much earlier than conventional ROP as also concluded by Shah et al. ${ }^{17}$

The gestational age of 11 babies lasered at CA 4 weeks was $\leq 28$ weeks in $8(72.72 \%)$ and 34 weeks in 3 $(27.27 \%)$ babies, therefore the benefit of screening at 2 weeks, should also be extended to babies above 28 weeks GA.

It is a known fact that preterm babies $\leq 28$ weeks are more susceptible to post treatment complications. ${ }^{21}$ Of the 11 babies who were lasered at 4 weeks, 6 babies with APROP belonging to $\leq 28$ weeks GA were the once who developed immediate post treatment complications, as early as few hours to one week. Post laser complications similar to our study have been reported following laser. ${ }^{22,23}$

None of the babies with conventional ROP, with $\geq$ GA 31 weeks treated at CA 4 weeks, developed post laser complication. Of the total number of babies lasered, 4 (7 eyes) babies required 2 sittings of laser. The second sitting of laser was completed with difficulty in eyes that developed complications immediately following laser. Hence, it is preferable to complete laser in one sitting especially in eyes with APROP. The use of intravitreal anti VEGF drugs might have averted such complication. ${ }^{24}$ Anti VEGF was restrictively used in babies with APROP, because of its pervasive effects on immature vascular retina in general. In the present study VEGF was used only in one baby. The baby did not have any immediate adverse effects. It is an accepted fact that anti VEGF promotes regression of ROP, however there is no general agreement to its use as a part of APROP protocol. $^{25}$

ROP regressed in 36 babies who underwent treatment except one baby with APROP progressed to stage 4A retinal detachment requiring lens sparing vitrectomy. The unfavorable outcome of laser among the APROP babies in our study was $2.7 \%$, whereas it was $18-30 \%$ by Anand et al and Shah et al. ${ }^{14,17}$

Table 1: Baseline characteristic of screened pre term babies $(\mathrm{N}=233)$

\begin{tabular}{|c|c|c|c|c|c|}
\hline & No ROP & ROP & P Value & $\begin{array}{c}\text { Lasered (\% of } \\
\text { ROP) }\end{array}$ & $\begin{array}{c}\text { APROP (\% of } \\
\text { ROP) }\end{array}$ \\
\hline Number of babies (\%) & $169(72.2 \%)$ & $64(27.8 \%)$ & & $36(56.25 \%)$ & $6(16.7 \%)$ \\
\hline \multicolumn{6}{|l|}{ Gestational Age(week) } \\
\hline Mean \pm Standard Deviation & $30.8 \pm 2.59$ & $29.28 \pm 2.49$ & $<0.0001$ & $29.81 \pm 2.68$ & $27.17 \pm 983$ \\
\hline Range & $24-36$ & $24-34$ & & $26-34$ & $26-28$ \\
\hline \multicolumn{6}{|l|}{ Birth Weight (grams) } \\
\hline Mean \pm Standard Deviation & $1418.53 \pm 382.26$ & $1204.38 \pm 359.819$ & 0.072 & $1216.11 \pm 321.50$ & $1103.33 \pm 145.56$ \\
\hline Range & $500-2500$ & $500-2100$ & & $500-1900$ & $900-1280$ \\
\hline $\begin{array}{l}\text { Multiple birth } \\
\mathrm{N}=27\end{array}$ & $13(48.15 \%)$ & 14 & - & 9 & $\begin{array}{c}5 \text { ( } 2 \text { pairs } \\
\text { One of the pair) }\end{array}$ \\
\hline $\begin{array}{l}\text { PMA at Laser Wk } \\
\text { mean } \pm \text { SD }\end{array}$ & - & - & & $36.85 \pm 30-48$ & $31.17 \pm 983$ \\
\hline CA at Laser WK Mean & - & - & & 7.1 & 4 weeks \\
\hline
\end{tabular}

Table 2: Association of GA and BW with Stages of ROP and treatment received

\begin{tabular}{|c|c|c|c|c|c|c|c|c|}
\hline & $\begin{array}{c}\text { Screened } \\
\mathrm{N},(\%)\end{array}$ & $\begin{array}{c}\text { No ROP N } \\
(\%)\end{array}$ & ROP N (\%) & \begin{tabular}{|c|} 
Stage 2 ROP \\
$\mathrm{N},(\%)$
\end{tabular} & $\begin{array}{c}\text { Stage } 3 \text { ROP } \\
\text { N, }(\%)\end{array}$ & $\begin{array}{c}\text { APROP } \\
\text { N, }(\%)\end{array}$ & $\begin{array}{l}\text { Stage } 4 \\
\mathrm{~N},(\%)\end{array}$ & $\begin{array}{c}\text { Treatable } \\
\text { ROP }\end{array}$ \\
\hline \multicolumn{9}{|c|}{ Gestational age (weeks) } \\
\hline$\leq 28$ & $65(27.9)$ & $32(18.9)$ & $33(51.6)$ & $14(53.8)$ & $12(36.4)$ & 6 & 1 & $16(44.4)$ \\
\hline $29-31$ & $55(23.6)$ & $38(22.5)$ & $17(26.6)$ & $7(29.2)$ & $10(30.3)$ & 0 & 0 & $10(27.8)$ \\
\hline $32-34$ & $98(42.1)$ & $84(49.7)$ & $14(21.9)$ & $3(12.5)$ & $11(33.3)$ & 0 & 0 & $10(27.8)$ \\
\hline$\geq 35$ & $15(6.4)$ & $15(8.9)$ & 0 & 0 & 0 & 0 & 0 & 0 \\
\hline Total & 233 & 169 & 64 & 24 & 33 & 6 & 1 & 36 \\
\hline \multicolumn{9}{|c|}{ Birth Weight (grams) } \\
\hline$\leq 1000$ & $35(15)$ & $14(8.3)$ & $21(32.8)$ & $9(37.5)$ & $9(27.27)$ & $2(33.3)$ & $1(100)$ & $9(25.0)$ \\
\hline $1001-1249$ & $50(21.5)$ & $34(20.1)$ & $16(25.0)$ & $6(25)$ & $7(21.21)$ & $3(50.0)$ & $0(0.0)$ & $10(27.8)$ \\
\hline $1250-1499$ & $45(19.3)$ & $32(18.9)$ & $13(20.3)$ & $4(16.6)$ & $8(24.24)$ & $1(16.6)$ & 0 & $9(25.0)$ \\
\hline $1500-1799$ & $62(26.6)$ & $52(30.8)$ & $10(15.6)$ & $3(12.5)$ & $7(21.21)$ & 0 & 0 & $7(19.4)$ \\
\hline$\geq 1800$ & $41(17.6)$ & $37(21.9)$ & $04(6.3)$ & $2(8.3)$ & $2(6.0)$ & 0 & 0 & $1(2.8)$ \\
\hline Total & 233 & 169 & 64 & 24 & 33 & 6 & 1 & 36 \\
\hline
\end{tabular}




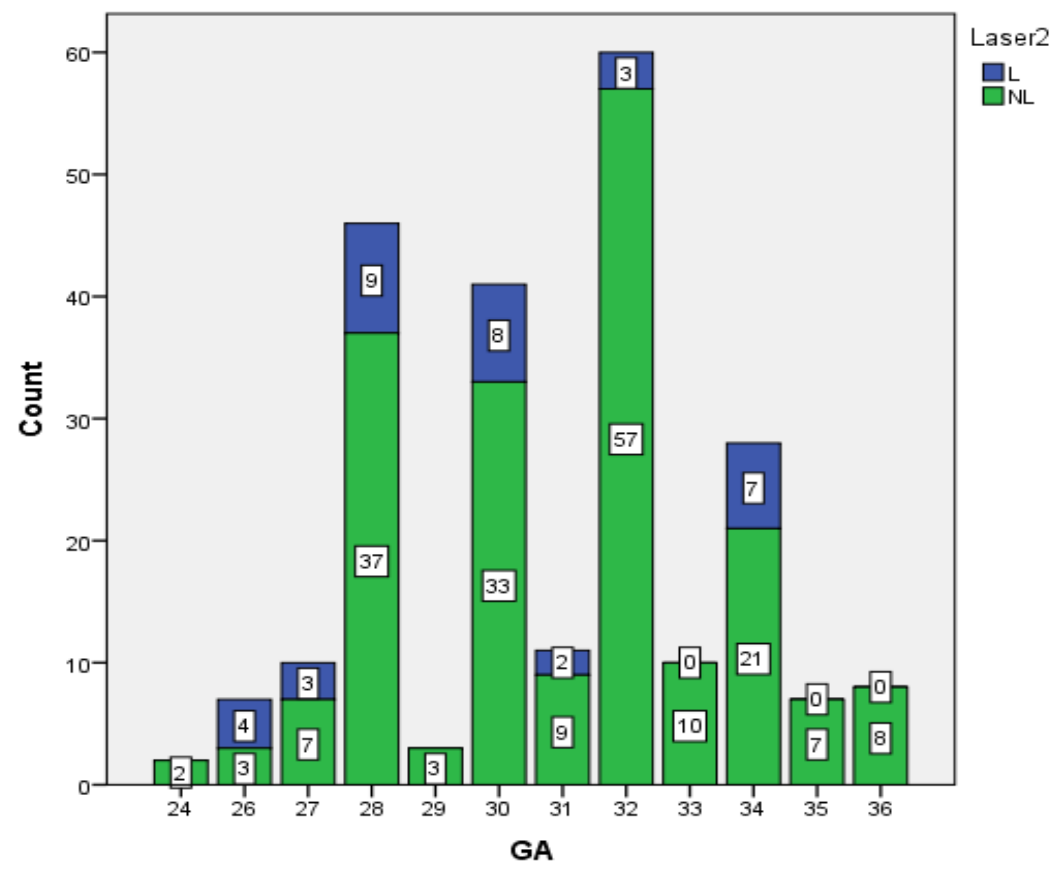

Fig. 1: Treatment pattern of screened babies according to the GA

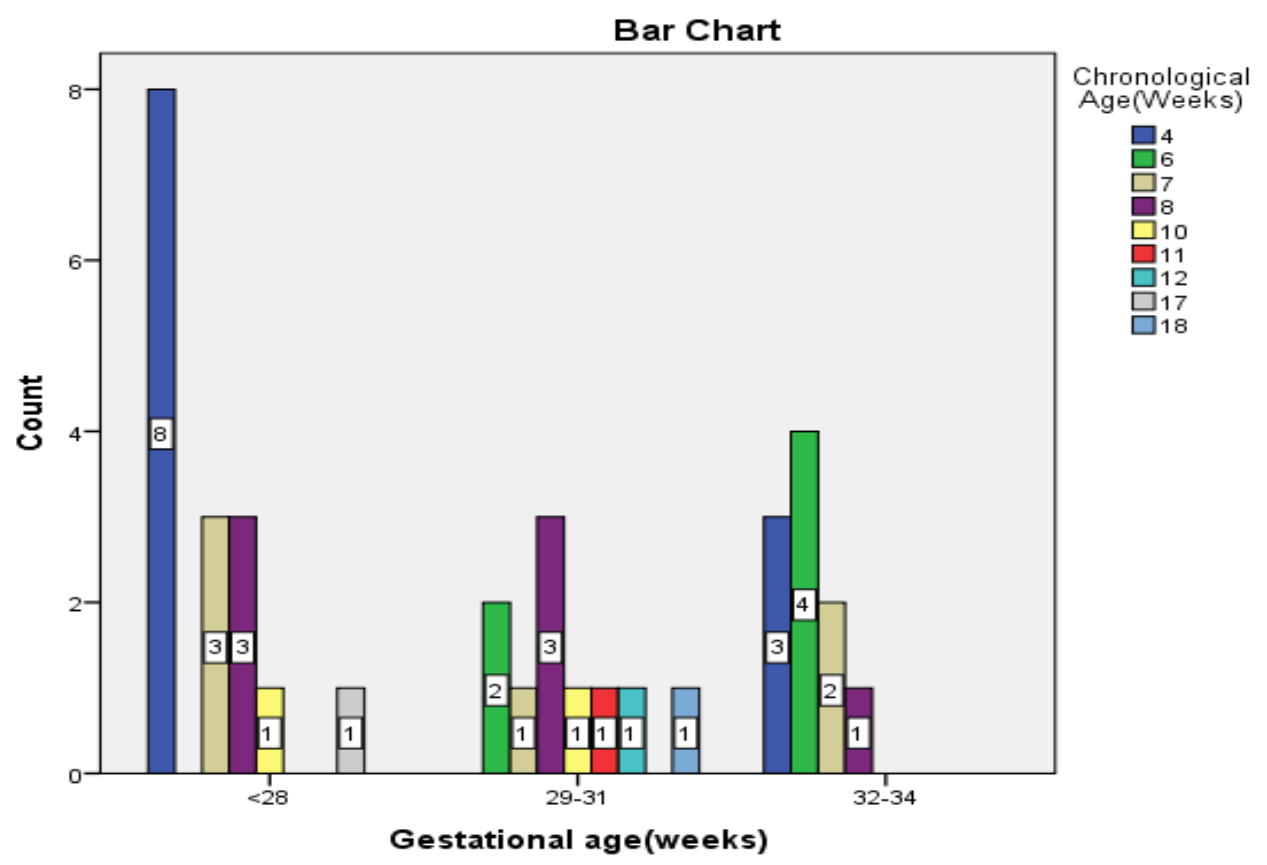

Fig. 2: Distribution of Lasered babies as per GA and CA 


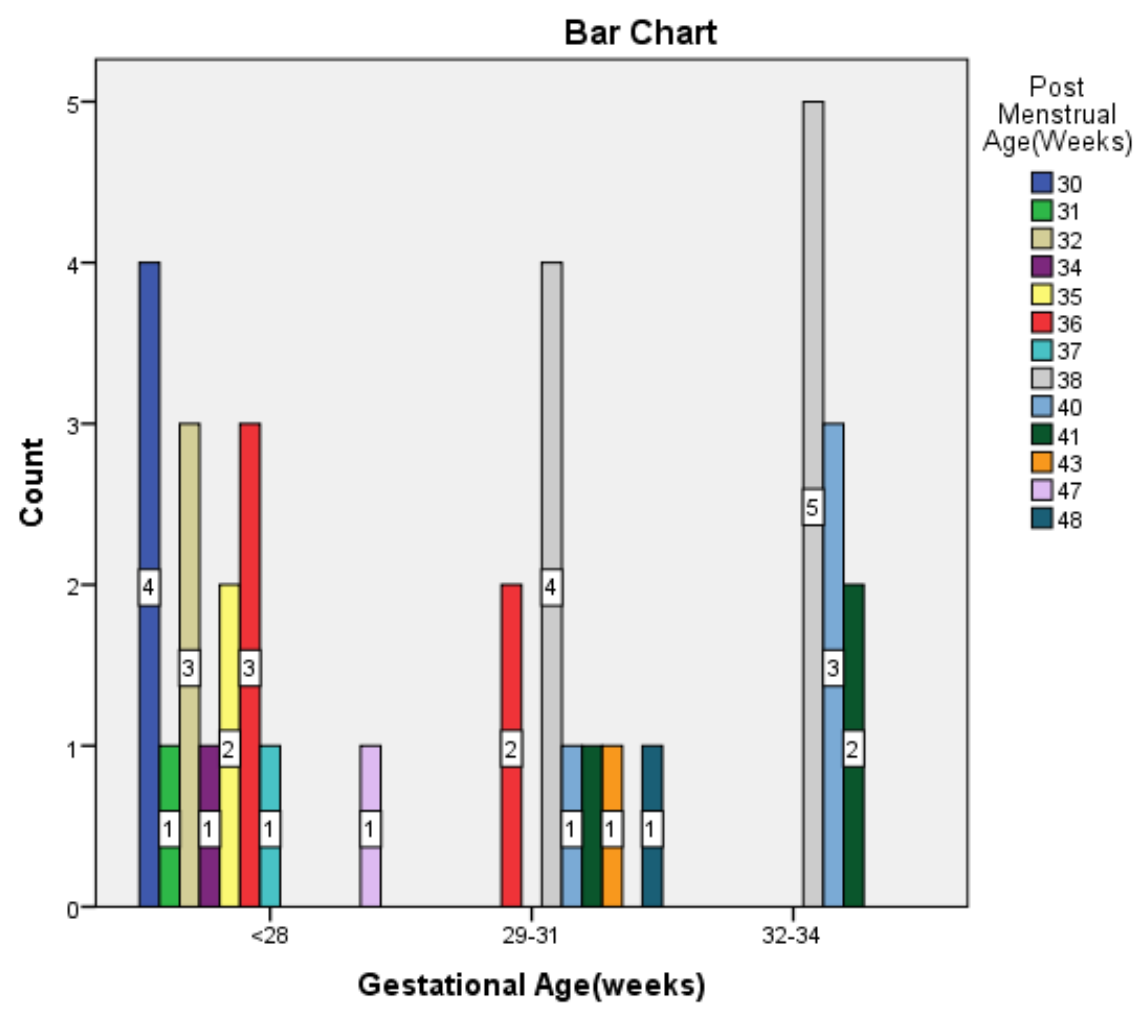

Fig. 3: Bar chart showing the GA versus PMA of lasered babies

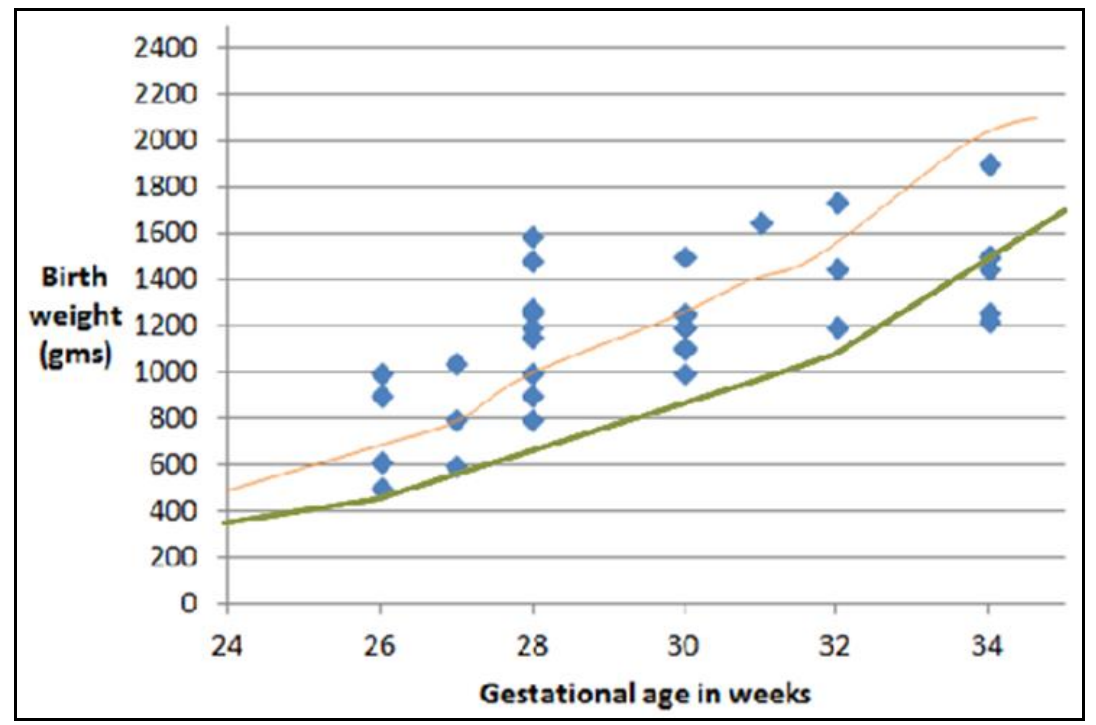

Fig. 4: The graph shows distribution of treated preterm babies in centile graph against birth weight and gestational age

\section{Conclusion}

The conclusion that could be drawn from the results of the present study are as follows: It was observed that of the two factors, GA and BW that influence the number and the severity of ROP, the role of GA is more critical factor than the birth weight. A substantial number of babies were lasered at 4 weeks of $\mathrm{CA}$ and hence the study validates the need for early screening as recommended by NNF guidelines and it is of advantage if the same benefit is extendable to babies upto 34 weeks GA. Immediate post laser complications, a characteristic of APROP babies supports, single sitting of laser as the most reliable approach in APROP.

\section{References}

1. Blencowe H, Lawn JE, Vazquez T, Fielder A, Gilbert C. Preterm-associated visual impairment and estimates of retinopathy of prematurity at regional and global levels for 2010. Pediatr Res. 2013;74(1):35-49. 
2. Statement P. Screening Examination of Premature Infants for Retinopathy of Prematurity. Pediatrics [Internet]. 2013;131(1):189-195.

3. Xu Y, Zhou X, Zhang Q, Ji X, Zhang Q, Zhu J, et al. Screening for retinopathy of prematurity in China: a neonatal units-based prospective study. Invest Ophthalmol Vis Sci. 2013;54(13):8229:8236.

4. Shan H, Ni Y, Xue K, Yu J, Huang X. Type 1 Retinopathy of Prematurity and Its Laser Treatment of Large Preterm Infants in East China. Chan-Ling T, editor. PLoS One [Internet]. 2015;10(12):e0144313. Available from: http://dx.plos.org/10.1371/journal.pone.0144313

5. Goyal A, Giridhar A, Gopalakrishnan M. Real-world scenario of retinopathy of prematurity in Kerala. Kerala $J$ Ophthalmol [Internet]. 2017 [cited 2018 Jan 17];29(1):30-34.

6. Jalali S, Kesarwani S, Hussain A. Outcomes of a Protocol-Based Management for Zone 1 Retinopathy of Prematurity: The Indian Twin Cities ROP Screening Program Report Number 2. Am J Ophthalmol [Internet]. 2011;151(4):719-724.e2.

7. Stout AU, Stout JT. Retinopathy of prematurity [Internet]. Vol. 50, Pediatric Clinics of North America. 2003;77-87. Available from: http://www.ontopin.org/ontop-pen/Week-12-13/ROP NNF Guidelines .pdf

8. Article $\mathrm{S}$. The International Classification of Retinopathy of Prematurity Revisited. Arch Ophthalmol [Internet]. 2005;123(7):991-999. Available from: http://archopht.jamanetwork.com/article.aspx?doi=10.100 1/archopht.123.7.991

9. Revised Indications for the Treatment of Retinopathy of Prematurity. Arch Ophthalmol [Internet]. 2003;121(12):1684-1694.

10. Jalali S, Azad R, Trehan HS, Dogra MR, Gopal L, Narendran V. Technical aspects of laser treatment for acute retinopathy of prematurity under topical anesthesia. Indian J Ophthalmol [Internet]. 2010;58(6):509-515.

11. Kandraju H, Agrawal S, Geetha K, Sujatha L, Subramanian S, Murki S. Gestational age-specific centile charts for anthropometry at birth for south Indian infants. Indian Pediatr [Internet]. 2012;49(3):199-202.

12. Chawla D, Agarwal R, Deorari A, Paul VK, Chandra P, Azad R. Retinopathy of prematurity. Indian J Pediatr. 2012;79(4):501-509.

13. Zin A, Gole GA. Retinopathy of Prematurity-Incidence Today. Clin Perinatol [Internet]. 2013;40(2):185-200.

14. Vinekar A, Dogra MR, Sangtam T, Narang A, Gupta A. Retinopathy of prematurity in Asian Indian babies weighing greater than 1250 grams at birth: ten year data from a tertiary care center in a developing country. Indian J Ophthalmol [Internet]. 2007;55(5):331-336.

15. Adams GGW, Bunce C, Xing W, Butler L, Long V, Reddy A, et al. Treatment trends for retinopathy of prematurity in the UK: active surveillance study of infants at risk. BMJ Open [Internet]. 2017;7(3):e013366.

16. Holmström G, Hellström A, Jakobsson P, Lundgren P, Tornqvist K, Wallin A. Evaluation of new guidelines for ROP screening in Sweden using SWEDROP - a national quality register. Acta Ophthalmol [Internet]. 2015;93(3):265-268.

17. Shah PK, Narendran V, Saravanan VR, Raghuram A, Chattopadhyay A, Kashyap M, et al. Fulminate retinopathy of prematurity - clinical characteristics and laser outcome. Indian J Ophthalmol [Internet]. 2005;53(4):261-265.

18. Sanghi G, Dogra MR, Katoch D, Gupta A. Aggressive posterior retinopathy of prematurity in infants $\geq 1500 \mathrm{~g}$ birth weight. Indian J Ophthalmol [Internet]. 2014;62(2):254-257.

19. Chen Y, Feng J, Gilbert C, Yin H, Liang J, Li X. Time at treatment of severe retinopathy of prematurity in China: Recommendations for guidelines in more mature infants. PLoS One. 2015;10(2):1-8.

20. Ho LY, Ho V, Aggarwal H, Ranchod TM, Capone A, Trese MT, et al. Management of avascular peripheral retina in older prematurely born infants. Retina. 2011;31(7):1248-1253.

21. Salgado CM, Celik Y, VanderVeen DK. Anterior Segment Complications After Diode Laser Photocoagulation for Prethreshold Retinopathy of Prematurity. Am J Ophthalmol [Internet]. 2010;150(1):69.e2.

22. Rundle P MF. Bilateral hyphaema following diode laser for retinopathy of prematurity. $\mathrm{Br} J$ Ophthalmol. 1995;79:1055-1056.

23. Parvaresh MM, Falavarjani KG, Modarres M, Nazari H, Saiepour N. Transscleral diode laser photocoagulation for type 1 prethreshold retinopathy of prematurity. $J$ Ophthalmic Vis Res. 2013;8(4):298-302.

24. Shah PK, Narendran V, Tawansy KA, Raghuram A, Narendran K. Intravitreal bevacizumab (Avastin) for post laser anterior segment ischemia in aggressive posterior retinopathy of prematurity. Indian J Ophthalmol [Internet]. 2007;55(1):75-76.

25. Chawla D, Darlow BA. Anti-Vascular Endothelial Growth Factor Preparations in the Treatment of Retinopathy of Prematurity: Balancing Risks and Benefits. Indian Pediatr [Internet]. 2016;53(2):S129-36.

How to cite this article: Anupama B, Jain R, Hegde V, Sudhir S, Shambhu R. A study of clinical profile and treatment outcome in pre term babies with retinopathy of prematurity. Ind J Clin Exp Ophthalmol. 2018;4(3):368373. 